
Not for reproduction, distribution or commercial use.

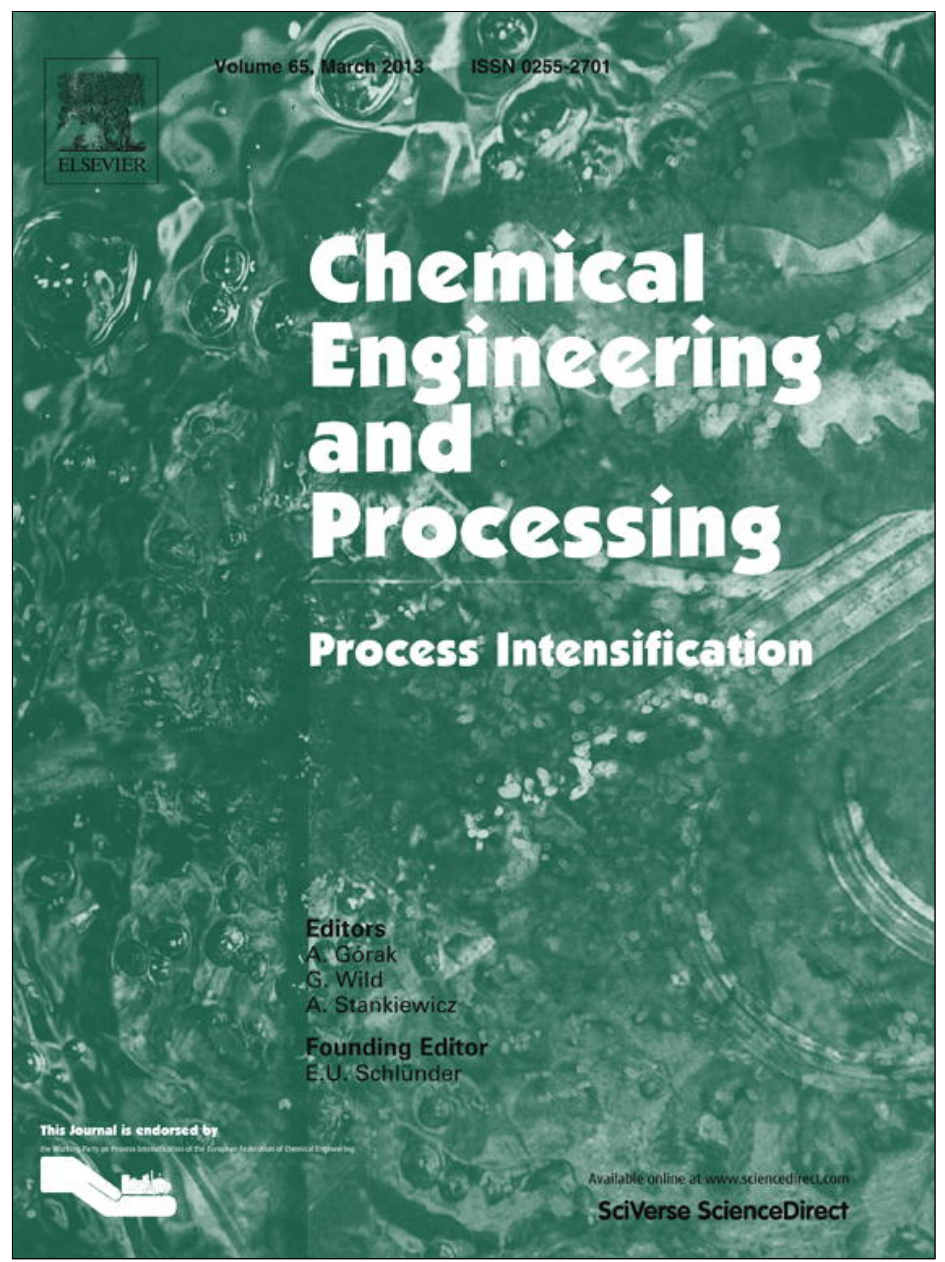

This article appeared in a journal published by Elsevier. The attached copy is furnished to the author for internal non-commercial research and education use, including for instruction at the authors institution and sharing with colleagues.

Other uses, including reproduction and distribution, or selling or licensing copies, or posting to personal, institutional or third party websites are prohibited.

In most cases authors are permitted to post their version of the article (e.g. in Word or Tex form) to their personal website or institutional repository. Authors requiring further information regarding Elsevier's archiving and manuscript policies are encouraged to visit:

http://www.elsevier.com/copyright 


\title{
A multi-objective approach for property-based synthesis of batch water networks
}

\author{
José Antonio Vázquez-Castillo a , José María Ponce-Ortega ${ }^{\text {b,* }}$, Juan Gabriel Segovia-Hernández a , \\ Mahmoud M. El-Halwagi ${ }^{c, d}$ \\ a Chemical Engineering Department, Universidad de Guanajuato, Campus Guanajuato, Gto., México 36005, Mexico \\ b Chemical Engineering Department, Universidad Michoacana de San Nicolás de Hidalgo, Morelia, Mich., México 58060, Mexico \\ ' Chemical Engineering Department, Texas A\&'M University, College Station, TX, USA \\ d Chemical and Materials Engineering Department, Faculty of Engineering, King Abdulaziz University, P.O. Box 80204, Jeddah 21589, Saudi Arabia
}

\section{A R T I C L E I N F O}

Article history:

Received 14 July 2012

Received in revised form 6 December 2012

Accepted 6 December 2012

Available online 17 December 2012

Keywords:

Mass and property integration

Mass exchange batch networks

Process intensification

Multi-objective optimization

Mathematical programming

\begin{abstract}
A B S T R A C T
This work introduces a multi-objective optimization approach for the synthesis of batch water networks. In addition to concentration-based constraints, water characteristics and property-based constraints for the process sinks are considered. Since adjusting properties may require the use of hazardous chemicals, issues of process intensification to minimize the total volume of stored materials are considered along with economic objectives. The model includes logical constraints, time restrictions, mass and property constraints for the sinks and environmental requirements. Two case studies are solved to show the applicability of the proposed approach. The results show tradeoffs between the storage of hazardous materials and the network economics. The multi-objective solutions are illustrated through Pareto curves that enable the decision maker to select the solutions that strike the proper balances between the desired objectives.
\end{abstract}

() 2012 Elsevier B.V. All rights reserved.

\section{Introduction}

Mass integration is a good strategy for the efficient use of the resources, minimizing the consumption of fresh resources and the discharges to the environment through the distribution and separation of the process streams in the process industry [1-3]. Sustainable design techniques must take into account the efficient utilization of fresh resources and the minimization of the environmental impact. In this context, several techniques for targeting the minimum wastewater discharge [4-10] and the minimum regeneration cost [11-15] have been proposed; these targeting techniques are very useful to identify targets before the design. In addition, in order to solve problems with multiple pollutants and to get optimal solutions with the corresponding design, some techniques for synthesizing water networks based on mathematical programming models have been reported [16-26]. Moreover, there have been reported several methodologies for synthesizing batch water networks based on the composition of the streams (see for example, Refs. [27-44]); and recently the concept of state-task-network representation has been applied to solve efficiently short-term batch optimization problems [45-47]. More recently, some improved strategies for recycling and reusing process streams based on the concept of property integration have been developed $[48,6]$. These strategies utilize property operators to characterize process streams instead of the traditionally utilized composition-based characterization, and also property-based mass integration approaches have been reported (see Refs. [49-57]). Under this strategy, the composition is also considered as a property in addition to other chemical, thermodynamic and physical properties constrained by the process sinks or by the environment (i.e., pH, toxicity, chemical oxygen demand, etc.). The property-based approach is suited for systems constituted by several components where is difficult to characterize the properties of the streams in the optimization process. Nevertheless, most of these methodologies have only considered continuous processes. Ng et al. [58] and Chen et al. [59] presented systematic approaches for synthesizing batch water networks based on the properties for streams constituted by several pollutants. These methodologies for property-based batch water integration represent significant improvements; however, they have only considered the minimization of the cost for the fresh water consumption. It is worth noting that the adjustment of properties (e.g., $\mathrm{pH}$ ) and treatment units may involve the storage of hazardous or toxic materials. Therefore, it is important to consider the merits of reducing the size of storage tanks and stored materials as part of process intensification $[60,61]$. The total storage of hazardous materials usually has not been considered as objective

\footnotetext{
* Corresponding author. Tel.: +52 443 3273584; fax: +52 4433273584

E-mail address: jmponce@umich.mx (J.M. Ponce-Ortega).
} 
to minimize during the synthesis of batch water networks. The total storage of hazardous materials as well as the number of storage tanks are related to the safety of the process, and nowadays it is quite interesting to account for this objective simultaneously with the economic objective (see Ref. [62]). Recently, a new definition for process intensification [61] includes any activity involving: (a) smaller equipment for given throughput; (b) higher throughput for given equipment size or given process; (c) less holdup for equipment or less inventory for process of certain material for the same throughput; (d) less usage of utility materials, and feedstock for a given throughput and given equipment size; or (e) higher performance for given unit size. Based on previous definition for process intensification, this paper is interested in point (c) accounting for minimizing the storage of hazardous materials in batch water networks. In addition, another interesting aspect of process intensification is the minimization of processing steps through process simplification (see Ref. [63]). Thus, this paper presents a multi-objective mixed integer nonlinear programming formulation based on streams properties for synthesizing intensified batch water networks (i.e., considering simultaneously minimizing the total annual cost (TAC) and the total storage of hazardous materials (TS) and accounting for the number of required processing units). The TAC consists of the cost for the fresh sources, the operational, variable and annualized fixed cost for the property treatment units and the cost for the required tanks. The organization of this paper is as follows: Section 2 provides the statement of the addressed problem, Section 3 presents the model formulation and also shows the description of the solution strategy of the addressed problem, Section 4 presents the analysis of the results, and finally Section 5 presents the conclusions.

\section{Problem statement}

The definition of the problem addressed in this paper is given as follows: given is a process with a set of process sinks (process units that require water with specific properties) $\operatorname{SINKS}=\left\{j \mid j=1,2, \ldots, N_{s i n k s}\right\}$, each process sink requires a known mass flow rate $\left(G_{j, t}\right)$, with specific properties or functionalities, which may include composition, density, $\mathrm{pH}$, viscosity, chemical oxygen demand, $\left(P_{j, p}^{i n}\right.$ Sink $)$, such a mass flow rate is required within a specific period of time. It is important to notice that the properties can represent any material property that can be measured in the streams, and that they are not restricted to thermodynamic properties. Also given is a set of process sources or process streams $S O U R C E S=\left\{i / i=1,2, \ldots, N_{\text {sources }}\right\}$, each process source can be segregated to be treated and consequently recycled and sent to the process sinks or to be discharged into the waste, the period of time in which each process source is available, the inlet mass flow rate and properties for each process source are fixed by the process and given by $W_{i, t}$ and $P_{i, p}^{i n}$ Source, respectively. Also, a set of fresh sources is available to feed any of the process sinks $F R E S H=\left\{r / r=1,2, \ldots, N_{\text {fresh }}\right\}$, the property values $\left(P_{r, p}^{\text {Fresh }}\right)$ for fresh sources are also known, the mass flow rates and the period of time in which any of these fresh sources sends mass flow rates to any sink are determined by the optimization process $\left(f_{r, j, t}\right)$. The process operations are performed over a known horizon of time $(H)$, which is divided in periods of time of $1 \mathrm{~h}$ of length. A set of units for the treatment of the streams to modify their properties (i.e., property interceptors) is also available; where the processing time and the efficiency are known parameters for each property interception unit. A set of storage tanks for the storage of intermediate treated process sources is also available; a class of these tanks is linked with each process source and another with each property interceptor, the relationship among property interceptors and storage tanks allows a state-task-network representation, where the states are represented by the storage tanks whereas the tasks are represented by the property interceptors. Finally, a set of environmental regulations that restrict the properties of the waste discharged to the environment is provided. The problem then consists in determining a batch network that satisfies the logical constraints, the time constraints, the process and environmental constraints, minimizing the total annual cost and the total mass stored. The total annual cost objective function includes the cost of fresh sources, the operating, variable and fixed costs for the property treatment units, and the cost for the storage tanks. On the other hand, the total storage objective function consists of the sum of the accumulated mass in all tanks in all periods of time.

Fig. 1 shows the batch network superstructure used in this work, such network has been built following a mass and property integration strategy; notice that the fresh sources are directly sent to the sinks without any treatment. On the other hand, the process sources may be treated or not treated, therefore, they are sent to storage tanks or sent to the waste, the last action is only performed if the environmental constraints are met, and this action avoids unnecessary storage of process streams which might contain hazardous substances, notice that this allows synthesizing batch water networks under the concept of process intensification [61], which is inherently related to the safety of a batch process considering the minimization of the storage of hazardous materials. The aim for including one tank for each stream is to avoid the mixing among process streams and the nonlinearities for the property balances in the model formulation. In the storage tanks, firstly the streams are segregated for the first set of treatment units, at the exit of each property interceptor the mass flow rate can be sent to the second set of treatment units or sent to the waste. Similarly for the subsequent set of property interceptors, and at the end of the treatment, the treated or untreated process streams can be directed to the sinks or to the waste.

Notice that the inlet and outlet properties in the property interceptors are related through a conversion factor (see Ref. [50]), which are modeled before the optimization process; therefore, the performance of each property interceptor is specified through a constant conversion factor and given processing time.

\section{Model formulation}

The mathematical model formulation is based on the batch superstructure shown in Fig. 1. The sets, indexes and notation used in the model are described in Nomenclature, and the proposed model is given as follows.

\subsection{Splitting of the fresh sources}

Every fresh source is segregated and directed to all process sinks:

$$
F_{r, t}=\sum_{j \in S I N K S} f_{r, j, t}, \quad \forall r \in \text { FRESH, } \quad t \in T
$$

Here, $F_{r, t}$ is the total mass flow rate for the fresh source $r$ and $f_{r j, t}$ is the mass flow rate sent to any sink $j$ at any time period $t$. 


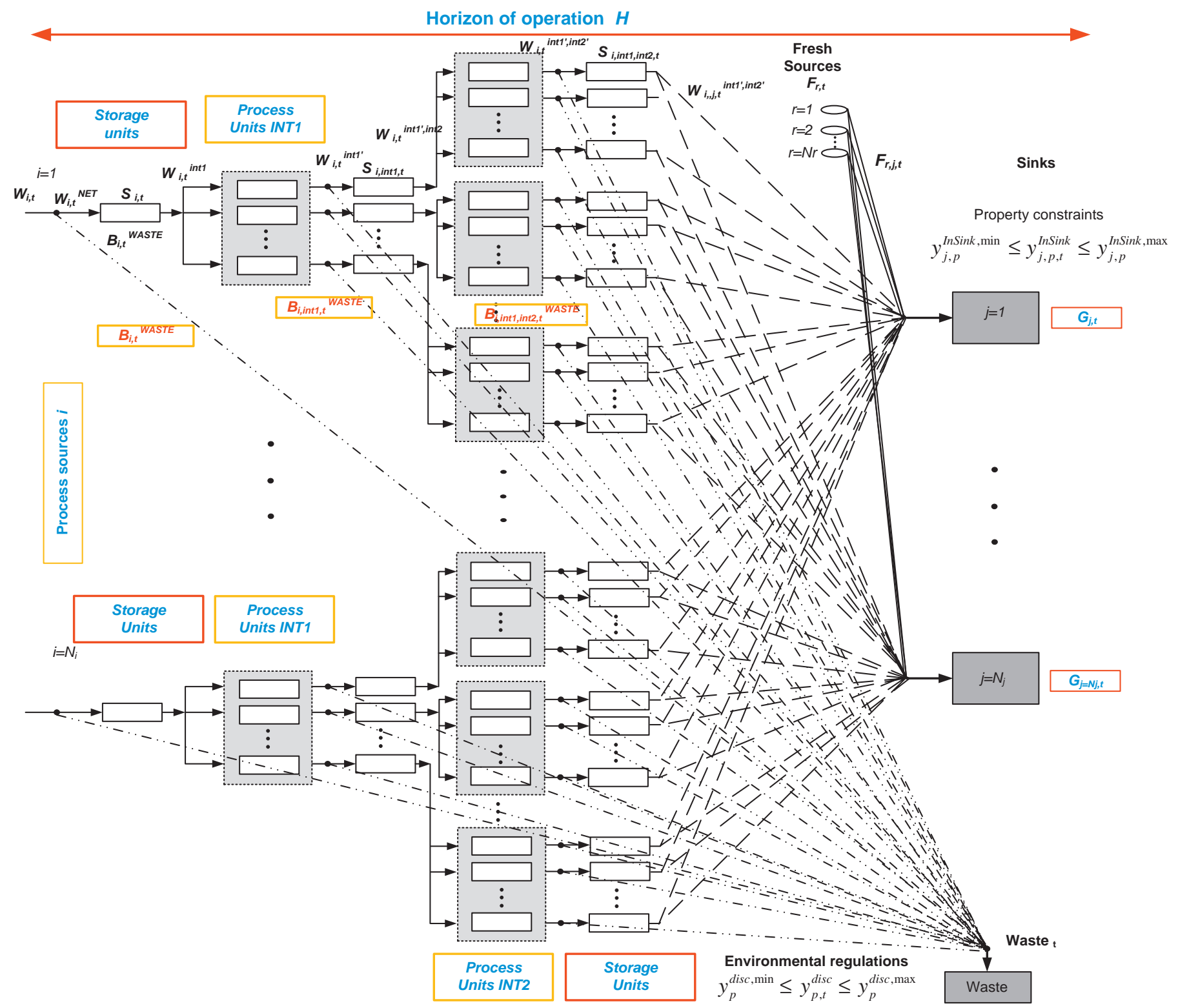

Fig. 1. Batch water network superstructure.

\subsection{Mass balance for the division of the process streams}

Each process stream can be directed to the treatment network or to the waste stream discharged to the environment:

$$
W_{i, t}=W_{i, t}^{\text {Net }}+B_{i, t}^{\text {Waste }}, \quad \forall i \in \text { SOURCES }, \quad t \in T
$$

where $W_{i, t}$ is the total mass flow rate of process stream $i$ at time $t, W_{i, t}^{\text {Net }}$ is the mass flow rate of process stream $i$ sent to the network, and $B_{i, t}^{\text {Waste }}$ is the mass flow rate sent to the waste stream discharged to the environment.

\subsection{Mass balance at the exit of interceptors $N$}

The mass balances for any property interceptor can be stated as follows:

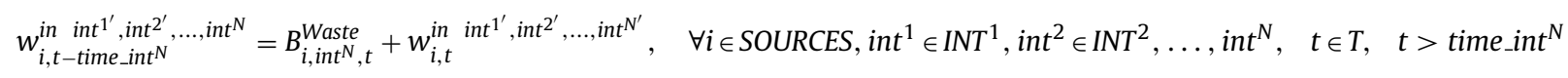

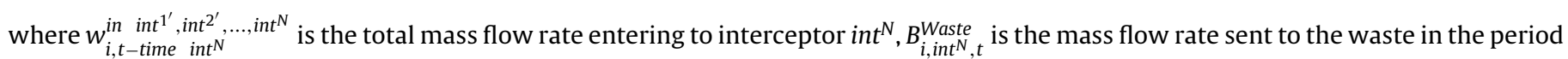
of time $t$ and, $w_{i, t}^{i n}$ int $1^{\prime}$, int $2^{\prime}, \ldots, i n t^{N^{\prime}}$ is the mass flow rate sent to tank int ${ }^{N}$. It is noteworthy that a fictitious treatment unit is used to model bypassing streams, which has a cost and an efficiency equal to zero. These fictitious interceptors are placed at the end of the set of the corresponding interceptors (see Fig. 1). 
3.4. Mass balance in tank int ${ }^{N}$ at the exit of the batch network

Once that all the properties have been treated, the treated process sources are sent to the process sinks, which is modeled as follows:

$$
\begin{aligned}
& S_{i, \text { int }^{1}, \text { int }^{2}, \ldots, \text { int }^{N}, t-1}+w_{i, t-1}^{\text {in int } 1^{1^{\prime}}, \text { int }^{2^{\prime}}, \ldots, \text { int }^{N^{\prime}}}=S_{i, i n t^{1}, \text { int }^{2}, \ldots, \text { int }^{N}, t}+\sum_{j \in \operatorname{SINKS}} w_{i, j, t}^{\text {int }^{1}, \text { int }^{2}, \ldots, \text { int }^{N}}, \\
& \forall i \in \text { SOURCES, int }{ }^{1} \in I N T^{1}, \text { int }^{2} \in I N T^{2}, \ldots, \text { int }^{N} \in I N T^{N}, \quad t \in T, \quad t>\text { time_int }^{N}
\end{aligned}
$$

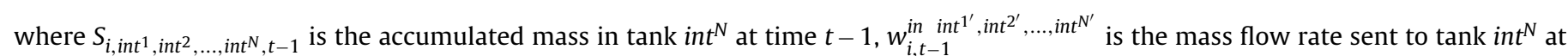

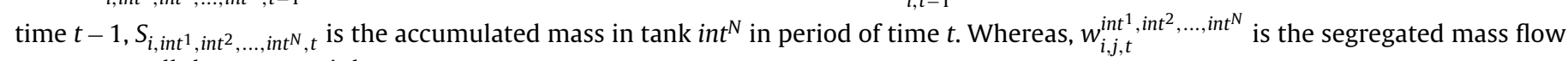
rate sent to all the process sinks.

\subsection{Overall mass balance at the mixing point prior to any sink}

The total mass flow rate entering to any sink consists of the sum of the mass flow rates of the segregated and treated process sources plus the fresh sources mass flow rates:

$$
G_{j, t}=\sum_{i \in \text { SOURCESint } 1} \sum_{\in I N T^{1}} \sum_{i n t^{2} \in I N T^{2}}, \ldots, \sum_{i n t^{N} \in I N T^{N}} w_{i, j, t-1}^{i n t^{1}, \text { int }^{2}, \ldots, i n t^{N}},+\sum_{r \in F R E S H} f_{r, j, t-1}, \quad \forall j \in \operatorname{SINKS}, \quad t \in T, \quad t>1
$$

Here, $G_{j, t}$ is the required mass flow rate of any sink at any period of time.

\subsection{Property balance at the mixing point prior to any sink}

Property balances for the properties constrained by the sinks are required to determine the values of the properties at the inlet conditions of the sinks:

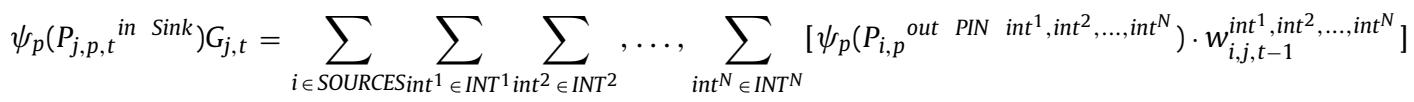

$$
\begin{aligned}
& +\sum_{r \in \text { FRESH }}\left[\psi_{p}\left(P_{r, p}{ }^{\text {in }}{ }^{\text {Fresh }}\right) f_{r, j, t-1}\right], \quad j \in \text { SINKS, } \quad p \in P, \quad t \in T, \quad t>1
\end{aligned}
$$

The mixing rules for properties used in Eq. (6) have been used and reported previously [48,6]. It is noteworthy that some mixing rules are linear whereas others are not; therefore, to avoid numerical complications with these nonlinearities, in this work the quantity given by the property operator $\psi_{p}\left(P_{j, p, t}\right.$ in Sink $)$ is used as optimization variable without the need to know the values of the properties at the inlet to the sinks, $P_{j, p, t}$ in Sink. Therefore, the sink constraints must also be given in terms of property operators $\psi_{p}\left(P_{j, p, t}\right.$ in $\left.\operatorname{Sink}\right)$ as shown in Eq. (12). Notice the inclusion of time, $t$, in the property operator which is important to take into account the dynamic nature of the property treatment units.

\subsection{Overall mass balance for the waste}

The total mass flow rate for the waste stream is given by the sum of all process streams that meet the environmental restrictions and the treated process streams in all the interceptors.

$$
\text { Waste }_{t}=\sum_{i \in \text { SOURCES }} B_{i, t-1}^{\text {Waste }}+\sum_{i n t^{1} \in I N T^{1}} B_{i, \text { int }^{1}, t-1}^{\text {Waste }}+\sum_{\text {int }^{2} \in I N T^{2}} B_{i, \text { int }^{2}, t-1}^{\text {Wate }}+, \ldots,+\sum_{i n t^{N} \in I N T^{N}} B_{i, \text { int }^{N} t-1}^{\text {Waste }^{\prime}}, \quad t \in T, t>1
$$

\subsection{Property balance for the waste}

There are needed property balances to determine the properties for the waste stream as follows:

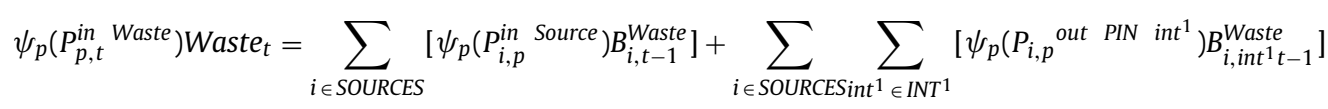

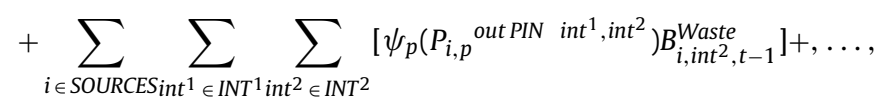

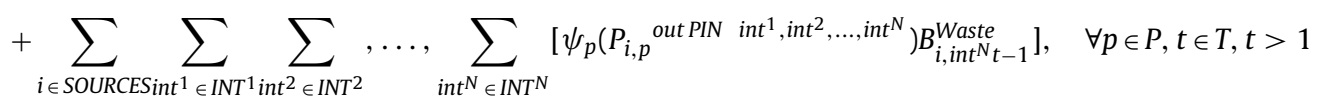

Notice that the properties for the streams change in the different periods of time and the environmental constraints for these properties must be satisfied in all periods. 
3.9. Mass flow rate constraints with respect to time (mass flow rate entering int ${ }^{N}$ )

These constraints can be generalized and stated as follows:

$$
\begin{aligned}
& w_{i, t}^{\text {in } \text { int }^{1^{\prime}}, \text { int }^{2^{\prime}}, \ldots, \text { int }^{N}}\left\{t \in T \mid t>\left(H-\text { time } \text { int }^{N}\right)\right\}=0, \quad \forall i \in \text { SOURCES, int }{ }^{1} \in I N T^{1}, \text { int }^{2} \in \\
& I N T^{2}, \ldots, \text { int }^{N} \in I N T^{N}, \quad t \in T, \quad t>\text { time int }
\end{aligned}
$$

Here, $w_{i, t}^{\text {in }}$ int $^{1^{\prime}}$, int $^{2^{\prime}}, \ldots$, int $t^{N}$ is the mass flow rate entering to interceptor $i n t^{N}$ (notice that there is not a subscript containing timeint ${ }^{1}$ in the above equation, then $w_{i, t}^{i n}$ int $^{1^{\prime}}$, int $^{2^{\prime}}, \ldots$, int ${ }^{N}$ is a mass flow rate entering to int $t^{N}$ in any period subject to the above constraint).

\subsection{Volume in tanks int ${ }^{N}$, a generalized formulation}

The volume of the tanks associated with property interceptors int ${ }^{N}$ is calculated as follows:

$$
V_{i, \text { int }}{ }^{1, i n t^{2}, \ldots, \text { int }^{N}, t}=\frac{S_{i, i n t^{1}, \text { int }^{2}, \ldots, \text { int }^{N}, t}}{\rho_{i}}, \quad i \in \text { SOURCES }, \quad \text { int } t^{1} \in I N T^{1}, \quad \text { int } t^{2} \in I N T^{2}, \ldots, \text { int }^{N} \in I N T^{N}, \quad t \in T
$$

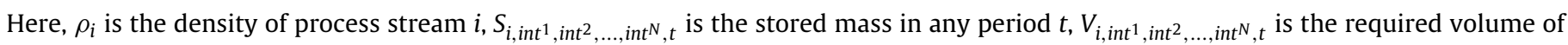
tank int ${ }^{N}$ at any period $t$.

Notice in Eq. (10) the way that the calculation of the required volume of the tanks is performed; in addition, this volume is a variable during the optimization process and also the volume for each tank changes in the different periods. Therefore, to determine the capacity for each tank there is required to determine the maximum volume required in all the periods to determine the capital cost. This is determined in the following relationships.

\subsection{Maximum volume in tanks int ${ }^{N}$}

$$
V_{i, \text { int }^{1}, \text { int }^{2}, \ldots, \text { int }^{N}} \geq V_{i, \text { int }^{1}, \text { int }^{2}, \ldots, \text { int }^{N}, t} \cdot \Delta t, i \in \text { SOURCES }, \quad \text { int } t^{1} \in I N T^{1}, \quad \text { int }^{2} \in I N T^{2}, \ldots, \text { int }^{N} \in I N T^{N}, \quad t \in T
$$

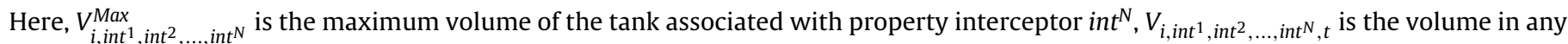
period $t, \Delta t$ is the length of time in which the mass is stored, it is only needed a period of time of $1 \mathrm{~h}$ for this calculation.

\subsection{Sink constraints}

Process sinks impose limits on the properties. Each process sink includes a set of specific process constraints. Regularly, process sinks constraint the composition of specific chemical compounds, density, $\mathrm{pH}$, viscosity, etc.:

$$
\psi_{p}\left(P_{j, p}{ }^{\min \operatorname{Sink}}\right) \leq \psi_{p}\left(P_{j, p, t}{ }^{\text {in Sink }}\right) \leq \psi_{p}\left(P_{j, p}{ }^{\max \text { Sink }}\right), \quad j \in N \text { SINKS, } \quad p \in P, \quad t \in T
$$

Notice that the process sink limits are imposed in terms of the property operators to avoid non-linear terms in Eq. (6).

\subsection{Environmental constraints}

The environmental regulations impose a set of constraints in terms of composition of hazardous materials and specific properties like toxicity, chemical oxygen demand, $\mathrm{pH}$, color, and odor, among others:

$$
\psi_{p}\left(P_{p}^{\min E n v}\right) \leq \psi_{p}\left(P_{p, t}{ }^{\text {in Waste }}\right) \leq \psi_{p}\left(P_{p}^{\max E n v}\right), \quad p \in P, \quad t \in T
$$

\subsection{Existence or inexistence of property interception units}

To determine the existence or inexistence of a property interceptor unit, a binary variable is needed; this variable is activated through a simple logical relationship using minimum and maximum known values of mass flow rates entering to any interceptor:

$$
\begin{aligned}
& w_{i, \text { int }^{1}, \text { int }^{2}, \ldots, \text { int }^{N}}^{\text {in }} \cdot y_{i, \text { int }^{1}, \text { int }^{2}, \ldots, \text { int }^{N}, t} \leq w_{i, t}^{\text {in } \text { int }^{1}, \text { int }^{2^{\prime}}, \ldots, \text { int }^{N}} \leq w_{i, \text { int }^{1}, \text { int }^{2}, \ldots, \text { int }^{N}}^{\text {in } \max ^{N}} \cdot y_{i, \text { int }^{1}, \text { int }^{2}, \ldots, \text { int }^{N}, t}, \quad \forall i \in \text { SOURCES }, \\
& \text { int }^{1} \in I N T^{1}, \text { int }^{2} \in I N T^{2}, \ldots, \text { int }^{N} \in I N T^{N}, \quad t \in T
\end{aligned}
$$

Notice that the binary variable $y_{i, \text { int }{ }^{1}, \text { int }^{2}, \ldots, i n t^{N}, t}$ could be activated or inactivated many times during different periods; therefore, there is needed a new binary variable $z_{i, i n t^{1}, \text { int }^{2}, \ldots, \text { int }}$ to specify that the interception unit associated with this first binary variable should only be taken into account just one time for purchase (for determining the capital cost). Therefore, a logical relationship between both binary variables is formulated as follows:

$$
1-y_{i, \text { int }^{1}, \text { int }^{2}, \ldots, \text { int }^{N}, t}+z_{i, \text { int }^{1}, \text { int }^{2}, \ldots, \text { int }^{N}} \geq 1, \quad \forall i \in \text { SOURCES }, \quad \text { int }{ }^{1} \in I N T^{1}, \text { int }^{2} \in I N T^{2}, \ldots, \text { int }^{N} \in I N T^{N}, \quad t \in T
$$

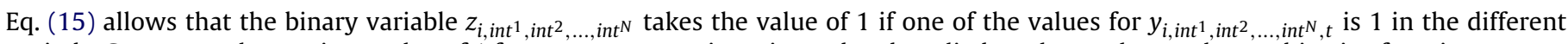
periods. Consequently, a unique value of 1 for $z_{i, i n t^{1}, i n t^{2}, \ldots, i n t^{N}}$ is registered and applied on the total annual cost objective function. 
Table 1

Environmental constraints for both case studies.

\begin{tabular}{llc}
\hline Property & Minimum & Maximum \\
\hline Composition $(\mathrm{ppm})$ & 0.005 & 0.05 \\
Toxicity $(\%)$ & 0 & 0.05 \\
$\mathrm{pH}$ & 5.5 & 9 \\
$\mathrm{COD}\left(\mathrm{kgO}_{2} / \mathrm{m}^{3}\right) \times 10^{3}$ & 0 & 75 \\
\hline
\end{tabular}

Table 2

Data for process and fresh streams for case study 1.

\begin{tabular}{|c|c|c|c|c|c|c|c|c|}
\hline $\begin{array}{l}\text { Sources } \\
i\end{array}$ & $\begin{array}{l}\text { Period } \\
t\end{array}$ & $\begin{array}{l}F \\
(\mathrm{~kg} / \mathrm{h})\end{array}$ & $\begin{array}{l}\text { Composition } \\
\text { (ppm) }\end{array}$ & $\begin{array}{l}\text { Toxicity } \\
(\%)\end{array}$ & $\mathrm{pH}$ & $\begin{array}{l}\mathrm{COD} \\
\left(\mathrm{kgO}_{2} / \mathrm{m}^{3}\right) \times 10^{3}\end{array}$ & $\begin{array}{l}\rho \\
\left(\mathrm{kg} / \mathrm{m}^{3}\right)\end{array}$ & $\begin{array}{l}\mu \\
(\mathrm{cP})\end{array}$ \\
\hline \multicolumn{9}{|c|}{ Process sources } \\
\hline 1 & 3 & 8083 & 0.016 & 0.3 & 5.4 & 0.187 & 908.00 & 1.256 \\
\hline 2 & 4 & 3900 & 0.024 & 0.5 & 4.8 & 92.10 & 1002.43 & 1.220 \\
\hline 3 & 5 & 3279 & 0.220 & 1.5 & 5.1 & 48.85 & 1046.47 & 1.261 \\
\hline \multicolumn{9}{|c|}{ Fresh sources } \\
\hline 1 & - & - & 0.00 & 0.0 & 7.0 & 0.00 & 1000.61 & 1.002 \\
\hline 2 & - & - & 0.01 & 0.1 & 6.8 & 0.01 & 1002.88 & 0.992 \\
\hline
\end{tabular}

\subsection{Existence or inexistence of storage tanks}

Similarly to the interception units, the existence or inexistence for the storage tanks is determined through logical relationships using binary variables.

First, for the tanks associated with the process sources:

$$
\begin{aligned}
& S_{i}^{\min } \cdot x_{i, t} \leq S_{i, t} \leq S_{i}^{\max } \cdot x_{i, t}, \quad \forall i \in \text { SOURCE }, \quad t \in T \\
& 1-x_{i, t}+w w_{i} \geq 1, \quad \forall i \in \text { SOURCES }, \quad t \in T
\end{aligned}
$$

Then, for the tanks associated with the property interceptors:

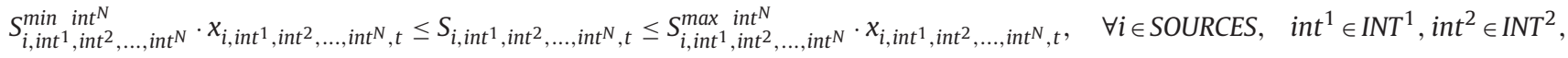

$$
\begin{aligned}
& \ldots, \text { int }^{N} \in I N T^{N}, \quad t \in T \\
& 1-x_{i, \text { int }^{1}, \text { int }^{2}, \ldots, \text { int }^{N}, t}+w w_{i, \text { int }^{1}, \text { int }^{2}, \ldots, \text { int }^{N}} \geq 1, \quad \forall i \in \text { SOURCES }, \quad \text { int }^{1} \in I N T^{1}, \text { int }^{2} \in I N T^{2}, \ldots, \text { int }^{N} \in I N T^{N}, \quad t \in T
\end{aligned}
$$

\subsection{Objective function}

The TAC is the unique objective function in most of the problems reported in literature [27-44], but in this paper the TS for the batch water network is also included as an objective function, which is aimed to take into account an innovative definition of process intensification [61], especially in reference to the minimization of storage of hazardous substances, under this concept in this paper has been developed a model from which is possible to determine a relationship between the total annual cost and the total storage to show the results through Pareto curves that tradeoff these objectives.

The objective function consists in the simultaneous minimization of the total annual cost (TAC) and the total mass stored (TS) for the batch water network; these two objectives are stated as follows:

$$
\min Z=\{T A C ; T S\}
$$

\subsubsection{Total storage objective function}

This objective function consists of the sum of the accumulated mass in all the tanks in all the periods of time. This objective function can be mathematically expressed in the following form:

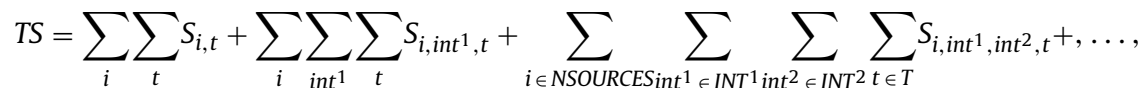

$$
\begin{aligned}
& +\sum_{i \in N S O U R C E S \text { int } 1} \sum_{\in I N T^{1}} \sum_{i n t^{2} \in I N T^{2}}, \ldots, \sum_{i n t^{N} \in I N T^{N}} \sum_{t \in T} S_{i, i n t^{1}, \text { int }^{2}, \ldots, i n t^{N}, t}
\end{aligned}
$$


3.16.2. Total annual cost objective function

The total annual costs objective function consists of the cost of fresh sources, the operational, variable and fixed costs of the property treatment units, the cost of tanks to store mass of process streams, and the cost of tanks associated with the interceptors for the treatment of properties. This objective function can be mathematically expressed as follows:

$$
\begin{aligned}
& \text { TAC }=\sum_{r \in \text { FRESH }} \sum_{t \in T} c_{r}^{\text {Unit }} \cdot F_{r, t} \cdot L_{B} \cdot N_{B}+\sum_{i \in \text { SOURCES }}\left(C_{i}^{\text {Fix.ST }} \cdot w_{i}+C_{i}^{\text {Var.ST }} \cdot\left(V_{i}^{\max }\right)^{\beta}\right) \cdot A_{f}
\end{aligned}
$$

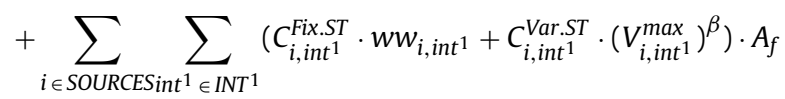

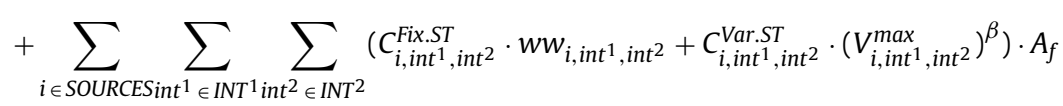

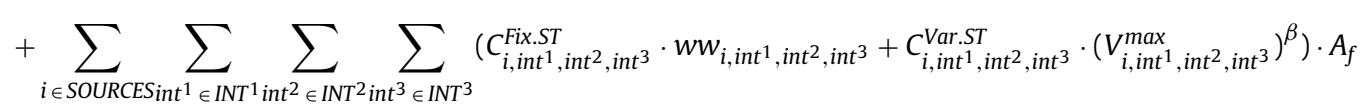

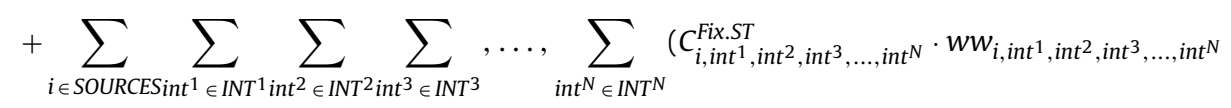

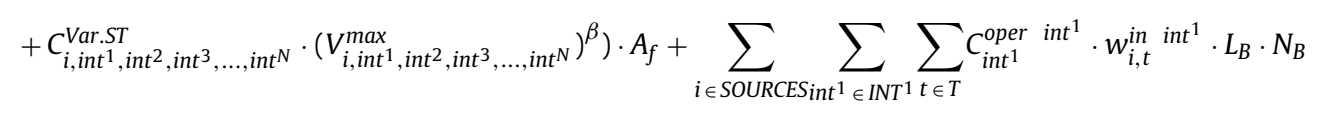

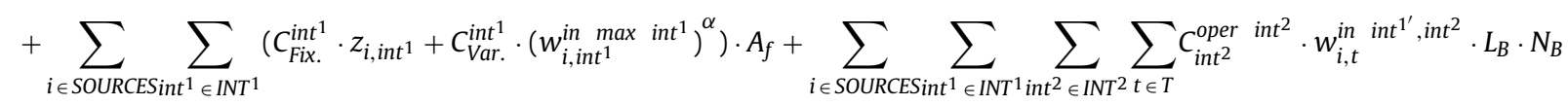

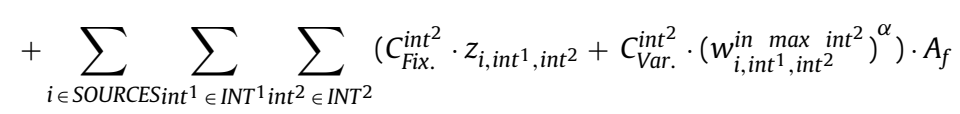

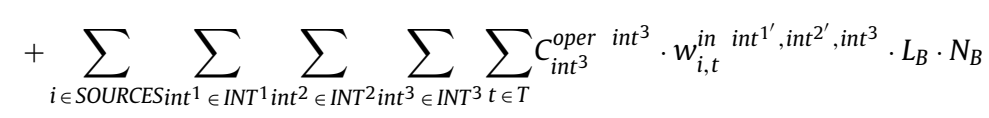

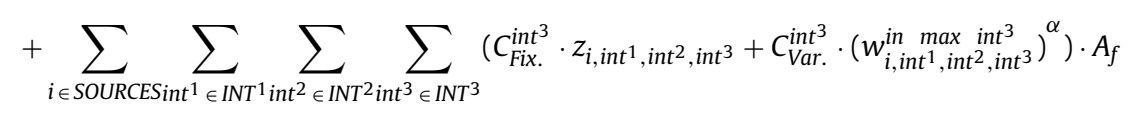

$$
\begin{aligned}
& +\sum_{i \in \text { SOURCESint } 1} \in \sum_{\in N T^{1}} \sum_{i n t^{2} \in I N T^{2}} \sum_{i n t^{3} \in I N T^{3}}, \ldots, \sum_{i n t^{N} \in I N T^{N}} \sum_{t \in T} C_{i n t^{N}}^{\text {oper int }}{ }^{N} \cdot w_{i, t}^{\text {in int }{ }^{1^{\prime}}, \text { int }^{2^{\prime}}, \text { int }^{3^{\prime}}, \ldots, \text { int }^{(N-1)^{\prime}}, \text { int }^{N}} \cdot L_{B} \cdot N_{B}
\end{aligned}
$$

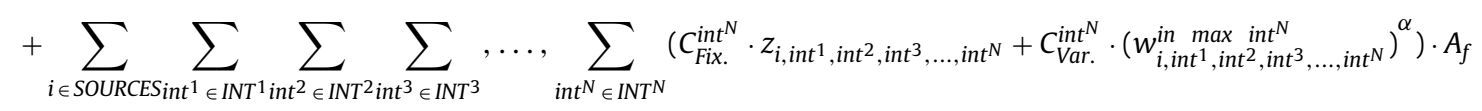

Finally, the optimization formulation consists in minimizing Eqs. (21) and (22) subject to restrictions given by Eqs. (1)-(20), which yields a moMINLP (multi-objective Mixed-Integer Non-Linear Programming Problem).

This formulation provides the advantage to deal with processes that may contain a considerable number of streams and components, so the values of the properties for each stream can be characterized through their corresponding property operators.

Notice that both objective functions are linear and that the non-linearity of the model appears in Eq. (8). The proposed batch water network superstructure considerably increases the number of variables and equations because this avoids the mixing of different process streams during the interception network; however, at the same time based on this representation the model is almost linear. Notice that only one non-linear term exists (i.e., a bilinear term) in the property balance for the waste stream (see Eq. (8)). One bilinear term is very easy to handle in the optimization process, and the references by Ponce-Ortega et al. [50,52] and Nápoles-Rivera et al. [51] have shown that in these models the global optimal solution can be rapidly found, and this solution is the same independently of the initial guesses. This way, the model is quasi-linear [50-52] (for which the global optimal solution is guaranteed); however, the problem size increases exponentially. The major problem to solve this large scale problem is the high number of binary variables; this way, an adequate approach has been proposed to solve this problem. Firstly notice that the binary variables are required to determine the fixed part of the capital cost for the treatment units and storage tanks, and this way the first step is to solve the associated quasi-linear problem without considering these binary variables (and the corresponding fixed part of the capital cost for the units), this first step yields a very good initial solution in a short CPU time because the combinatorial problem is avoided. Then, the solution obtained in the step one is used as initial solution for solving the original quasi-linear problem involving the binary variables (and also the corresponding fixed part for the capital cost of the units). Notice that this very good initial solution helps to eliminate most of the branches of the search tree in the branch and bound procedure for solving the combinatorial problem; this way, in a moderate CPU time the associated problem for the second step can reach the global optimal solution.

\section{Results and discussion}

This section presents the application of the proposed moMINLP to two case studies. Table 1 shows the environmental constraints used for both case studies. For the optimal design and operation of batch water networks, the operation of the plant has been given (previously 
Table 3

Process sinks data and limits for case study 1 .

\begin{tabular}{|c|c|c|c|c|c|c|c|c|c|}
\hline $\begin{array}{l}\text { Sinks } \\
j\end{array}$ & $\begin{array}{l}\text { Period } \\
t\end{array}$ & $\begin{array}{l}G \\
(\mathrm{~kg} / \mathrm{h})\end{array}$ & $\begin{array}{l}\text { Comp. Max. } \\
\text { (ppm) }\end{array}$ & $\mathrm{pH}^{\text {Min. }}$ & $\mathrm{pH}^{\text {Max. }}$ & $\begin{array}{l}\rho^{\text {Min. }} \\
\left(\mathrm{kg} / \mathrm{m}^{3}\right)\end{array}$ & $\begin{array}{l}\rho^{\text {Max. }} \\
\left(\mathrm{kg} / \mathrm{m}^{3}\right)\end{array}$ & $\begin{array}{l}\mu^{\text {Min. }} \\
(\mathrm{cP})\end{array}$ & $\begin{array}{l}\mu^{\text {Max. }} \\
(\mathrm{cP})\end{array}$ \\
\hline 1 & 10 & 6000 & 0.013 & 5.3 & 8.0 & 1271.2 & 817.20 & 0.900 & 1.202 \\
\hline 2 & 15 & 4400 & 0.011 & 5.4 & 7.8 & 1135.0 & 771.80 & 0.905 & 2.230 \\
\hline 3 & 21 & 2490 & 0.100 & 5.2 & 8.2 & 1316.6 & 819.47 & 0.903 & 1.260 \\
\hline
\end{tabular}

Table 4

Data of property interceptors for case study 1 .

\begin{tabular}{|c|c|c|c|c|c|c|}
\hline Property & Interceptor & $\begin{array}{l}\text { Processing } \\
\text { time }(\mathrm{h})\end{array}$ & $\begin{array}{l}\text { Conversion } \\
\text { factor }\end{array}$ & $\begin{array}{l}\text { Operating cost } \\
(\$ / \mathrm{kg})\end{array}$ & Fixed cost $(\$)$ & $\begin{array}{l}\text { Variable cost } \\
\text { (\$/period) }\end{array}$ \\
\hline \multirow[t]{2}{*}{ Composition } & $\mathrm{REC}^{1}$ & 2 & 0.02 & 0.0065 & 8000 & 25 \\
\hline & $\mathrm{REC}^{2}$ & 2 & 0.15 & 0.0033 & 7000 & 18 \\
\hline \multirow{2}{*}{ Toxicity } & TOX $^{1}$ & 2 & 0 & 0.0075 & 9000 & 15 \\
\hline & $\mathrm{TOX}^{2}$ & 2 & 0.1 & 0.0063 & 8200 & 12 \\
\hline \multirow[t]{3}{*}{ COD } & $\mathrm{AER}^{1}$ & 1 & 0.2 & 0.0055 & 6800 & 13 \\
\hline & $\mathrm{AER}^{2}$ & 1 & 0.3 & 0.0043 & 5200 & 11 \\
\hline & $\mathrm{NEU}^{1}$ & 1 & 0.5 & 0.0085 & 5200 & 16 \\
\hline \multirow{3}{*}{$\mathrm{pH}$} & $\mathrm{NEU}^{2}$ & 1 & 0.7 & 0.0093 & 4800 & 14 \\
\hline & $\mathrm{NEU}^{3}$ & 1 & 1.5 & 0.0055 & 3700 & 13 \\
\hline & $\mathrm{NEU}^{4}$ & 1 & 1.3 & 0.0065 & 2900 & 12 \\
\hline
\end{tabular}

optimized); and for the case studies presented the batch is repeated in a daily basis; therefore the optimization for the batch water networks is carried out for each day (because this operation is the same through the year). A horizon of operation of $24 \mathrm{~h}$ as the length of batch was fixed, 333 batches per year and $7992 \mathrm{~h}$ of yearly operation were considered to solve both cases. The constraint method was implemented in the software GAMS (General Algebraic Modeling Systems) and the solvers DICOPT/CONOPT/CPLEX were used to solve the resulting MINLP/NLP/LP problems (see [64]) using a computer with an Intel Core i7 processor at $2.6 \mathrm{GHz}$ and $9 \mathrm{~GB}$ of RAM. Thus, one of the objectives is transformed as a limit (TS), and the problem consists in minimizing the other objective (TAC) yielding a single objective constrained problem. In this way, this single objective problem can be solved for different levels for the constraint to obtain a Pareto set of optimal solutions (see Ref. [65] for details of the constraint method).

\subsection{Case study 1}

The data for this example were taken from Ref. [50], and the example was adjusted to consider batch processes. The example consists of three process sources and two fresh sources, the unit cost of the fresh sources are $\$ 0.009 / \mathrm{kg}$ for $r=1$ and $\$ 0.006 / \mathrm{kg}$ for $r=2$. Table 2 shows the data for the process streams and fresh sources, four properties can be treated with exception of density and viscosity. This is because usually density and viscosity are not treated in the process industries [1]; to treat these properties there is required to add or remove mass from the process streams (or change temperature). However, for this case study, it is possible to satisfy the process sinks constraint by mixing different process streams and fresh sources with different densities and viscosities. Therefore, in this case there is not required to include interceptors for the density and viscosity. However, for the cases where there are required interceptors for density or viscosity, such interceptors must be included in the model. On the other hand, Table 3 presents the process sink constraints, whereas the data for the property interception units are shown in Table 4, where two units to treat composition, toxicity and chemical oxygen demand were considered, and four units were considered for the neutralization process (two for acidity and two for alkalinity). In addition, a fictitious property treatment unit has been included in each set of property interception units (not listed in Table 4), which means that the mass flow rate passing through that unit does not require treatment.

This problem involves 124,299 variables and 144,156 constraints, and Fig. 2 shows the Pareto curve that compensate both objective functions; notice that each point of this curve represents a batch network configuration that meets all the restrictions stated by the model, the last point in the right hand side of Fig. 2 corresponds to the configuration with the minimum TAC and maximum TS (i.e., 449,977 USD/year and $50,776 \mathrm{~kg} /$ batch, respectively). On the other hand, the last point in the left hand side of Fig. 2 corresponds to the configuration with

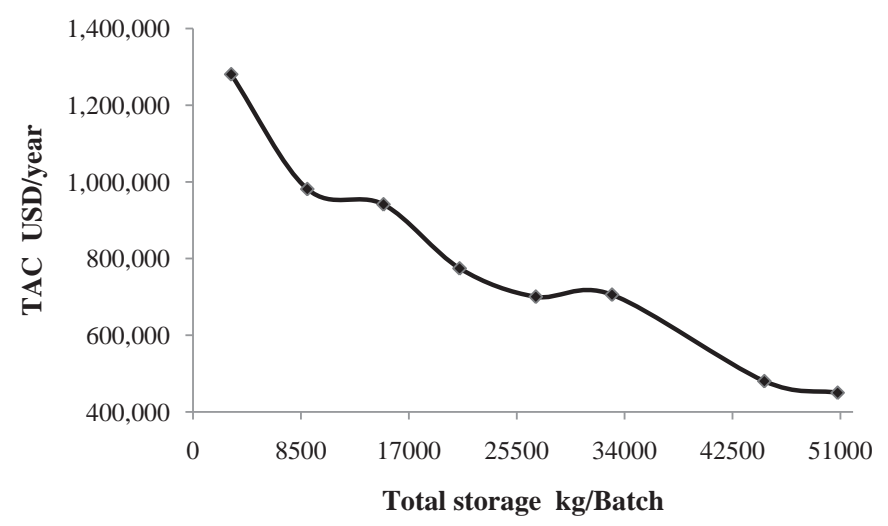

Fig. 2. Pareto curve for case study 1. 
Table 5

Results for case study 1.

\begin{tabular}{|c|c|c|c|c|c|}
\hline $\begin{array}{l}\text { TAC } \\
\text { (USD/year) }\end{array}$ & $\begin{array}{l}\text { Total storage } \\
\text { (kg/batch) }\end{array}$ & $\begin{array}{l}\text { Fresh resources } \\
(\mathrm{kg} / \text { batch })\end{array}$ & $\begin{array}{l}\text { Waste } \\
\text { (kg/batch) }\end{array}$ & $\begin{array}{l}\text { Property } \\
\text { interceptors }\end{array}$ & $\begin{array}{l}\text { Storage } \\
\text { tanks }\end{array}$ \\
\hline $449,977.11$ & 50,776 & 1188.192 & 3560.191 & 6 & 4 \\
\hline $480,406.48$ & 45,000 & 1297.750 & 3669.750 & 9 & 6 \\
\hline $705,777.39$ & 33,000 & 2287.102 & 4659.102 & 11 & 7 \\
\hline $700,412.61$ & 27,000 & 2265.697 & 5273.619 & 10 & 6 \\
\hline $774,377.98$ & 21,000 & 3454.389 & 5826.389 & 10 & 5 \\
\hline $941,210.9$ & 15,000 & 3632.590 & 6004.590 & 10 & 3 \\
\hline $981,533.66$ & 9000 & 3622.918 & 5994.918 & 10 & 3 \\
\hline $1,280,517.3$ & 3000 & 4775.241 & 7147.241 & 11 & 2 \\
\hline
\end{tabular}

the maximum TAC and minimum TS (i.e., 1,280,517 USD/year and $3000 \mathrm{~kg} / \mathrm{batch}$, respectively). Between these two extreme configurations there is a marked difference in the values for the objective functions, firstly the TAC shows an increase of $184 \%$, whereas the TS drops $94 \%$. These changes can be explained by analyzing Table 5, which provides the results for TAC, TS, fresh resources consumption, waste discharged to the environment, total number of property interception units and storage tanks. For the configuration with minimum TAC a total of 6 property interceptors units and 4 storage tanks are required, on the other hand for the configuration with the highest TAC a total of 11 property interceptors units and 2 tanks are required, it is observed in Table 5 and in Fig. 2, where as the TS decreases the TAC exhibits an opposite behavior, whereas in most of the configurations the total number of property interceptors almost remains constant. This behavior indicates that the increment in the total number of property interceptor units in the batch networks configurations is directly related with the increase in the TAC; in addition, as the mass flow rate sent to the waste increases the amount of needed fresh resources also increases, consequently an increase in the TAC is linked to this tradeoff too.

Fig. 3 shows the Gantt chart for the batch water network with minimum TAC for the case study 1, it is noteworthy that all the environmental, process and time constraints are fulfilled in this configuration.

\subsection{Case study 2}

This case study has also been previously reported by Ponce-Ortega et al. [50] for the continuous case, these data have been adjusted to convert it into a batch process. This example consists of six process sources and three fresh sources, the unit costs for the fresh sources are $\$ 0.03 / \mathrm{kg}$ for $r=1, \$ 0.02 / \mathrm{kg}$ for $r=2$ and $\$ 0.01 / \mathrm{kg}$ for $r=3$. Table 6 shows the data for the process streams and fresh sources, four properties were treated with exception of density and viscosity, to satisfy the constraints for these last two properties, mixing different process streams and fresh sources is enough in this case study. On the other hand, Table 7 provides the process sinks constraints, whereas the data for the property interception units are shown in Table 8. In this case, the same number of property interception units as in case 1 is used.

This problem is larger than the problem of the case study 1, because this involves 309,322 variables and 288,058 constraints. Table 9 provides the results for the case study 2. The Pareto curve for this case study is shown in Fig. 4, the extreme right point corresponds to the

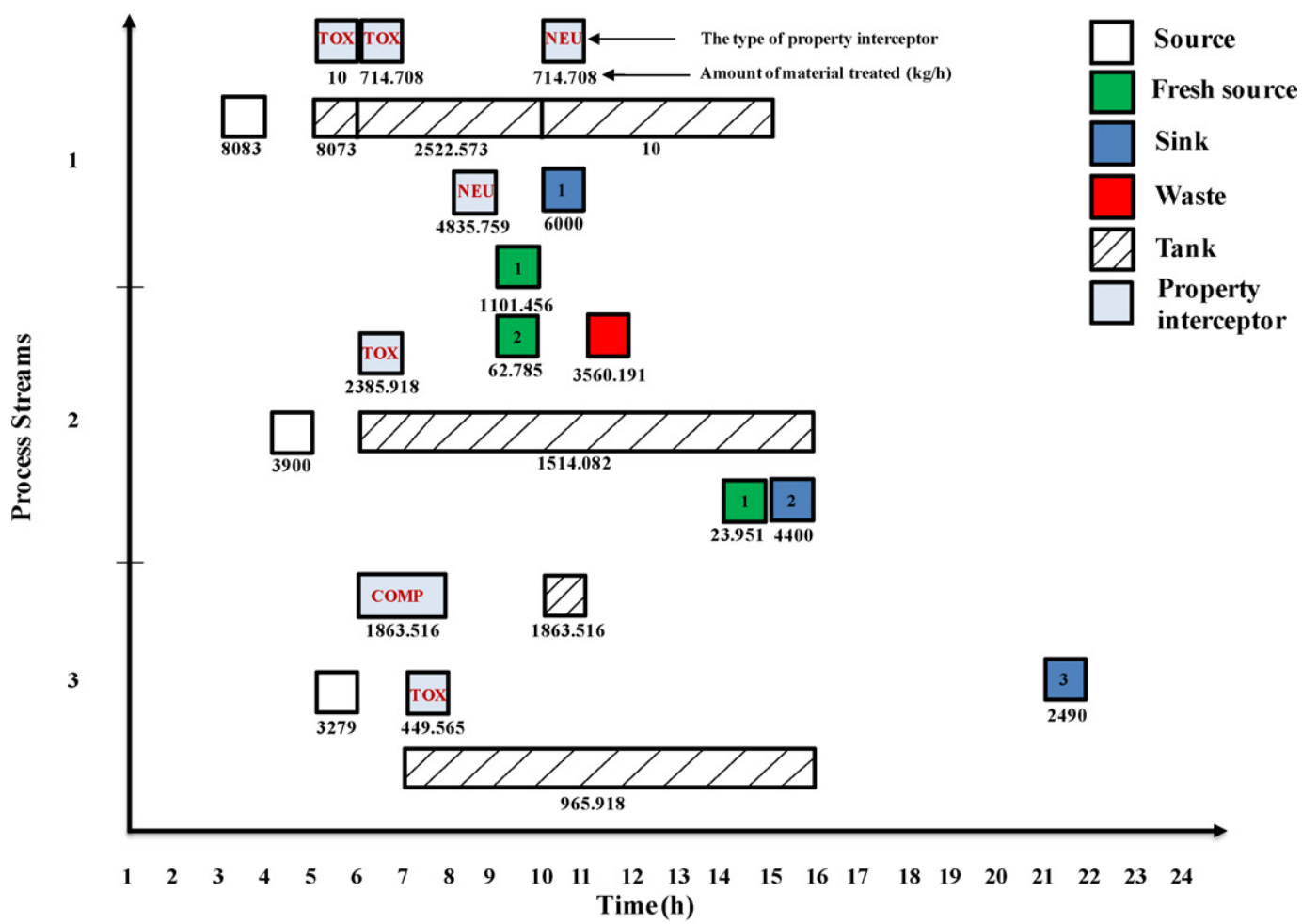

Fig. 3. Gantt chart for the batch water network with minimum TAC for case study 1. 
Table 6

Data for process and fresh streams for case study 2.

\begin{tabular}{|c|c|c|c|c|c|c|c|c|}
\hline $\begin{array}{l}\text { Sources } \\
i\end{array}$ & $\begin{array}{l}\text { Period } \\
t\end{array}$ & $\begin{array}{l}F \\
(\mathrm{~kg} / \mathrm{h})\end{array}$ & $\begin{array}{l}\text { Composition } \\
(\mathrm{ppm})\end{array}$ & $\begin{array}{l}\text { Toxicity } \\
(\%)\end{array}$ & $\mathrm{pH}$ & $\begin{array}{l}\text { COD } \\
\left(\mathrm{kgO}_{2} / \mathrm{m}^{3}\right) \times 10^{3}\end{array}$ & $\begin{array}{l}\rho \\
\left(\mathrm{kg} / \mathrm{m}^{3}\right)\end{array}$ & $\begin{array}{l}\mu \\
(\mathrm{cP})\end{array}$ \\
\hline \multicolumn{9}{|l|}{ Process sources } \\
\hline 1 & 3 & 1088 & 0.460 & 0.5 & 4.8 & 78.850 & 908.00 & 1.256 \\
\hline 2 & 4 & 816 & 0.570 & 0.9 & 4.7 & 89.210 & 1002.43 & 1.220 \\
\hline 3 & 5 & 1587 & 0.490 & 0.7 & 5.2 & 105.408 & 914.99 & 1.241 \\
\hline 4 & 6 & 698 & 0.395 & 1.8 & 5.1 & 50.470 & 910.04 & 1.520 \\
\hline 5 & 7 & 1791 & 0.290 & 1.9 & 5.4 & 20.587 & 959.75 & 1.620 \\
\hline 6 & 8 & 1351 & 0.054 & 1.4 & 5.8 & 110.547 & 1095.04 & 1.201 \\
\hline \multicolumn{9}{|l|}{ Fresh sources } \\
\hline 1 & - & - & 0.000 & 0.0 & 7.0 & 0.00 & 1000.61 & 1.002 \\
\hline 2 & - & - & 0.010 & 0.1 & 6.8 & 0.01 & 1002.88 & 0.992 \\
\hline 3 & - & - & 0.015 & 0.8 & 7.5 & 0.50 & 1225.80 & 1.005 \\
\hline
\end{tabular}

Table 7

Process sinks data and limits for case study 2.

\begin{tabular}{|c|c|c|c|c|c|c|c|c|c|}
\hline $\begin{array}{l}\text { Sinks } \\
j\end{array}$ & $\begin{array}{l}\text { Period } \\
t\end{array}$ & $\begin{array}{l}G \\
(\mathrm{~kg} / \mathrm{h})\end{array}$ & $\begin{array}{l}\text { Comp. }{ }^{\text {Max. }} \\
\text { (ppm) }\end{array}$ & $\mathrm{pH}^{\text {Min. }}$ & $\mathrm{pH}^{\operatorname{Max} .}$ & $\begin{array}{l}\rho^{\text {Min. }} \\
\left(\mathrm{kg} / \mathrm{m}^{3}\right)\end{array}$ & $\begin{array}{l}\rho^{\operatorname{Max}} \\
\left(\mathrm{kg} / \mathrm{m}^{3}\right)\end{array}$ & $\begin{array}{l}\mu^{\text {Min. }} \\
(\mathrm{cP})\end{array}$ & $\begin{array}{l}\mu^{\operatorname{Max} .} \\
(\mathrm{cP})\end{array}$ \\
\hline 1 & 10 & 544 & 0.050 & 5.30 & 8.0 & 1271.20 & 817.20 & 0.900 & 1.202 \\
\hline 2 & 13 & 1152 & 0.150 & 5.40 & 7.8 & 1135.0 & 771.80 & 0.905 & 2.230 \\
\hline 3 & 15 & 446 & 0.015 & 5.20 & 8.2 & 1316.60 & 839.90 & 0.903 & 1.260 \\
\hline 4 & 17 & 712 & 0.001 & 5.35 & 7.5 & 1302.980 & 898.92 & 0.915 & 1.250 \\
\hline 5 & 19 & 521 & 0.010 & 5.50 & 8.4 & 1293.90 & 875.312 & 0.925 & 1.249 \\
\hline 6 & 21 & 394 & 0.005 & 5.60 & 9.4 & 1356.098 & 852.158 & 1.003 & 1.350 \\
\hline
\end{tabular}

Table 8

Data of property interceptors for case study 2.

\begin{tabular}{|c|c|c|c|c|c|c|}
\hline Property & Interceptor & $\begin{array}{l}\text { Processing } \\
\text { time (h) }\end{array}$ & $\begin{array}{l}\text { Conversion } \\
\text { factor }\end{array}$ & $\begin{array}{l}\text { Operating cost } \\
(\$ / \mathrm{kg})\end{array}$ & $\begin{array}{l}\text { Fixed cost } \\
(\$)\end{array}$ & $\begin{array}{l}\text { Variable cost } \\
\text { (\$/period) }\end{array}$ \\
\hline \multirow[t]{2}{*}{ Composition } & $\mathrm{REC}^{1}$ & 2 & 0.02 & 0.0143 & 8000 & 25 \\
\hline & $\mathrm{REC}^{2}$ & 2 & 0.15 & 0.0073 & 7000 & 18 \\
\hline \multirow[t]{2}{*}{ Toxicity } & $\mathrm{TOX}^{1}$ & 1 & 0 & 0.0216 & 6500 & 28 \\
\hline & $\mathrm{TOX}^{2}$ & 1 & 0.1 & 0.0165 & 5900 & 21 \\
\hline \multirow[t]{2}{*}{ COD } & $\mathrm{AER}^{1}$ & 1 & 0.2 & 0.0143 & 7200 & 27 \\
\hline & $\mathrm{AER}^{2}$ & 1 & 0.45 & 0.0071 & 6400 & 19 \\
\hline \multirow{4}{*}{$\mathrm{pH}$} & $\mathrm{NEU}^{1}$ & 1 & 0.5 & 0.1389 & 5200 & 16 \\
\hline & $\mathrm{NEU}^{2}$ & 1 & 0.7 & 0.0397 & 4800 & 14 \\
\hline & $\mathrm{NEU}^{3}$ & 1 & 1.5 & 0.1433 & 3700 & 13 \\
\hline & $\mathrm{NEU}^{4}$ & 1 & 1.3 & 0.0419 & 2900 & 12 \\
\hline
\end{tabular}

Table 9

Results for case study 2 .

\begin{tabular}{|c|c|c|c|c|c|}
\hline $\begin{array}{l}\text { TAC } \\
\text { (USD/year) }\end{array}$ & $\begin{array}{l}\text { Total storage } \\
\text { (kg/batch) }\end{array}$ & $\begin{array}{l}\text { Fresh resources } \\
\text { (kg/batch) }\end{array}$ & $\begin{array}{l}\text { Waste } \\
\text { (kg/batch) }\end{array}$ & $\begin{array}{l}\text { Property } \\
\text { interceptors }\end{array}$ & $\begin{array}{l}\text { Storage } \\
\text { tanks }\end{array}$ \\
\hline $1,295,022.3$ & 12,489 & 557.884 & 4119.893 & 16 & 10 \\
\hline $1,320,256.7$ & 9616 & 557.709 & 4119.850 & 18 & 11 \\
\hline $1,326,141.2$ & 6000 & 557.708 & 4119.849 & 24 & 7 \\
\hline $1,418,959.5$ & 4000 & 784.378 & 4346.377 & 22 & 6 \\
\hline $1,487,947.7$ & 3000 & 936.336 & 4498.335 & 23 & 4 \\
\hline
\end{tabular}

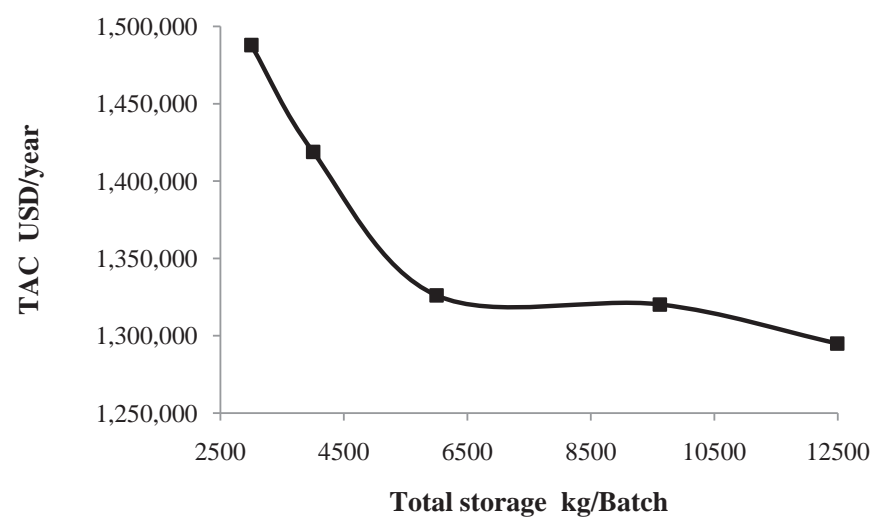

Fig. 4. Pareto curve for case study 2. 


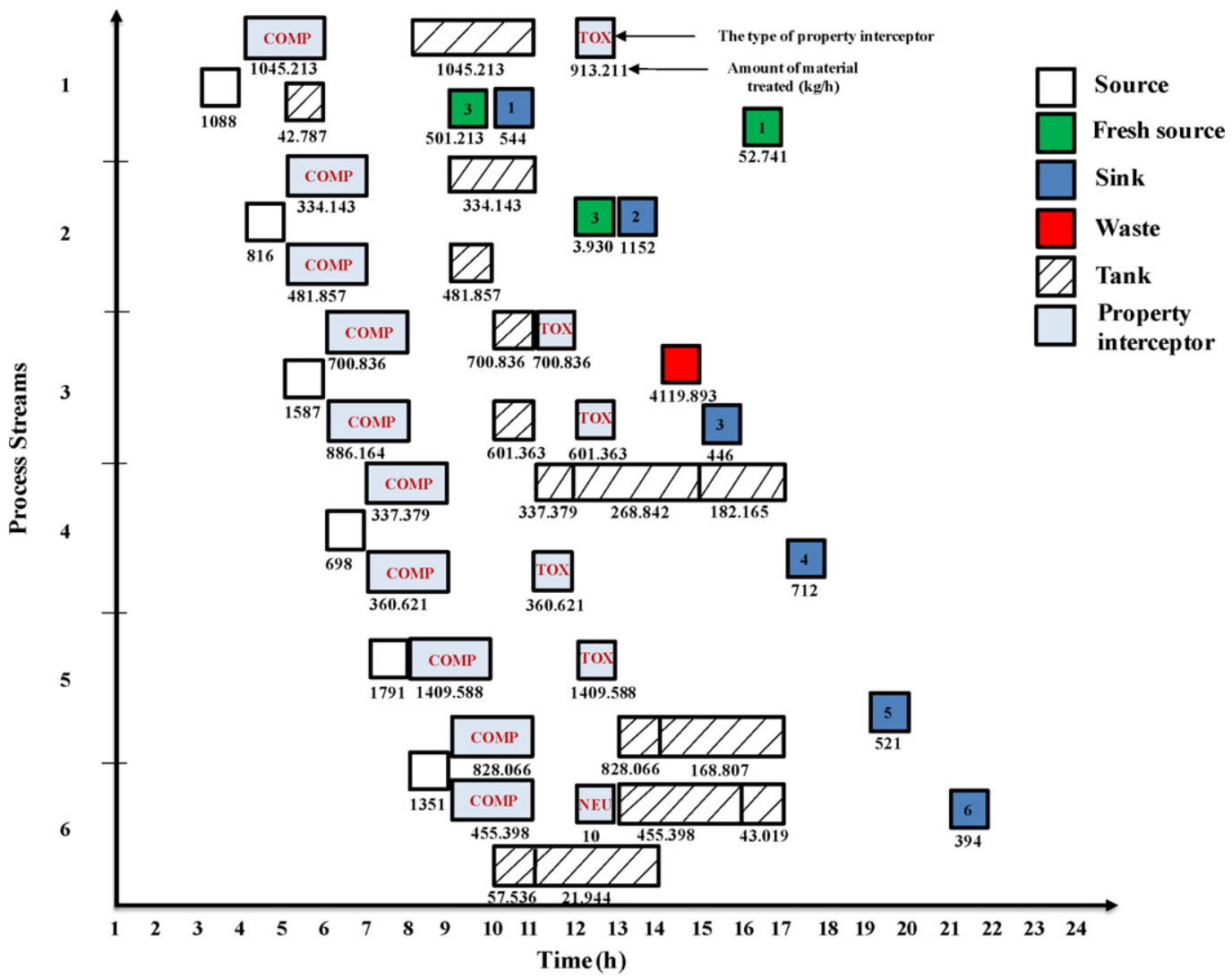

Fig. 5. Gantt chart for the batch water network with minimum TAC for case study 2.

batch network configuration with the minimum TAC and maximum TS $(1,295,022 \mathrm{USD} / \mathrm{year}$ and 12,489 kg/batch, respectively). In the left extreme of Fig. 4, the point that represents the configuration with the maximum TAC and minimum TS is located (1,487,947 USD/year and $3000 \mathrm{~kg} / \mathrm{batch}$, respectively). There is a significant difference in terms of the TAC between these two configurations, where an increase of $14.9 \%$ in the TAC is observed, the difference is larger with respect to TS for both configurations, where a decrement of 76\% is observed. Notice in Fig. 4 and Table 9 that as the batch network configuration approaches to the minimum $T S$, the waste discharged to the environment increases and so does the TAC. The increase in the TAC is a consequence of the increment in the total number of property interceptor units, and the increase in the use of fresh resources.

Fig. 5 shows the Gantt chart for the batch water network with minimum TAC for the case study 2.

\title{
5. Conclusions
}

This paper has introduced a systematic approach for synthesizing batch water networks. The approach incorporates the concept of process intensification through the simultaneous minimization of the TAC and the total storage of the hazardous materials in the batch processes. This total storage of hazardous materials as well as the number of storage tanks are related to the safety of the process, and nowadays it is quite interesting to account for this safety objective simultaneously with the economic objective. A multi-objective MINLP formulation has been developed. In addition to tracking mass and properties of the streams over the time horizon, the model formulation accounts for logical constraints linked to binary variables, time restrictions, property sinks constraints and property environmental constraints. The proposed multi-objective MINLP is quasi-linear and therefore global optimal solutions are guaranteed, despite of the large number of variables the proposed solution strategy is easily implemented. Two case studies have been solved to show the applicability of the proposed approach. The results show the tradeoffs between cost and extent of intensification.

\section{Acknowledgment}

The authors acknowledge SEP-CONACYT Grant 130207 for financial support.

\section{Appendix A. Nomenclature}

\author{
Parameters \\ $A_{f} \quad$ factor used to annualize the inversion \\ $c \quad$ unit cost of fresh source \\ C costs of tanks or interceptors (see subscripts and superscripts for details)
}


$G \quad$ required mass flow rate of any sink

$H \quad$ horizon of operation

$L_{B} \quad$ length of batch

$N_{B} \quad$ number of batches per year

$\alpha \quad$ exponential factor associated to the size of equipment

$\beta \quad$ exponential factor associated to the size of equipment

$\Delta t \quad$ length of period

\section{Variables}

B mass flow rate

$F \quad$ mass flow rate of fresh stream

$f \quad$ mass flow rate of fresh stream sent to any sink at any time

$S \quad$ mass stored in tanks

TAC total annual cost objective function

TS total storage objective function

$V \quad$ volume of the tanks for the storage of process streams

$W \quad$ mass flow rate from process stream sent to tank

$w \quad$ segregated mass flow rate sent to property interceptors

Waste mass flow rate sent to the waste discharged to the environment

$w w \quad$ binary variable to denote the existence of tanks

$x \quad$ binary variable to denote the existence of tanks in any period of time

$y \quad$ binary variable to denote the existence of property interceptors in any period of time

$z \quad$ binary variable to denote the existence of property interceptors

$\psi \quad$ property operator

\section{Sets}

FRESH fresh sources

INT $T^{1} \quad$ property interceptors for property 1

$I N T^{2} \quad$ property interceptors for property 2

$I N T^{N} \quad$ property interceptors for property $N$

$P \quad$ properties

SINKS process sinks

SOURCES process streams

$T \quad$ periods of time

\section{Subscripts}

$i \quad$ process sources or process streams

int ${ }^{1} \quad$ property interceptors for the treatment of property 1

int $^{2} \quad$ property interceptors for the treatment of property 2

int $^{N} \quad$ property interceptors for the treatment of property $N$

Fix fixed cost of property interceptor

j process sink

$p \quad$ property

$r \quad$ fresh source

$t \quad$ period of time

Var variable cost of property interceptor

\section{Superscripts}

Fix.ST fixed cost of storage tanks

Fresh fresh source

in mass flow rate entering to any tank or property interceptor

int ${ }^{1^{\prime}} \quad$ tanks linked to property interceptors for property 1

int ${ }^{2^{\prime}} \quad$ tanks linked to property interceptors for property 2

int $\mathrm{N}^{N^{\prime}} \quad$ tanks linked to property interceptors for property $N$

max maximum

Net the entrance of mass flow rate to the network

Oper operating cost of property interceptor

out PIN the exit of property interception network

Sink any sink

Source process source or process streams

Unit unit cost of fresh source

Var.ST variable cost of storage tanks

Waste waste 


\section{References}

[1] M.M. El-Halwagi, Sustainable Design through Process Integration: Fundamentals and Applications to Industrial Pollution Prevention, Resource Conservation, and Profitability Enhancement, Butterworth-Heinemann/Elsevier, Waltham, MA, USA, 2012.

[2] M.M. El-Halwagi, Process Integration, Academic Press, New York, 2006.

[3] M.M. El-Halwagi, H.D. Spriggs, Solve design puzzles with mass integration, Chemical Engineering Progress 94 (8) (1998) $25-44$.

[4] W.C.J. Kuo, R. Smith, Designing for the interactions between water-use and effluent treatment, Chemical Engineering Research and Design 76 (A3) (1998) 287-301.

[5] N. Hallale, A new graphical targeting method for water minimization, Advances in Environment Research 6 (3) (2002) 377-390.

[6] M.M. El-Halwagi, F. Gabriel, D. Harell, Rigorous graphical targeting for resource conservation via material recycle/reuse networks, Industrial and Engineering Chemistry Research 42 (19) (2003) 4319-4328.

[7] Z.A. Manan, Y.L. Tan, D.C.Y. Foo, Targeting the minimum water flow rate using water cascade analysis technique, AIChE Journal 50 (12) (2004) $3169-3183$.

[8] D.C.Y. Foo, Z.A. Manan, Y.L. Tan, Use cascade analysis to optimize water networks, Chemical Engineering Progress 102 (7)(2006) 45-52.

[9] A.M. Almutaq, M.M. El-Halwagi, An algebraic targeting approach to resource conservation via material recycle/reuse, International Journal of environment and Pollution $29(1-3)(2007) 4-18$

[10] S. Bandyopadhyay, C.C. Cormos, Water management in process industries incorporating regeneration and recycle through a single treatment unit, Industrial and Engineering Chemistry Research 47 (4) (2008) 1111-1119.

[11] W.C.J. Kuo, R. Smith, Design of water-using systems involving regeneration, Process Safety and Environmental Protection 76 (B2) (1998) $94-114$.

[12] V. Agrawal, U.V. Shenoy, Unified conceptual approach to targeting and design of water and hydrogen networks, AIChE Journal 52 (3) (2006) 1071-1081.

[13] D.K.S. Ng, D.C.Y. Foo, R.R. Tan, Targeting for total water network. Part 2: waste treatment targeting and interactions with water systems elements, Industrial and Engineering Chemistry Research 46 (26) (2007) 9114-9125.

[14] J. Bai, X. Feng, C. Deng, Graphically based optimization of a single contaminant regeneration reuse water systems, Chemical Engineering Research and Design 85 (A8) (2007) 1178-1187.

[15] X. Feng, J. Bai, X.S. Zheng, On the use of graphical method to determine the targets of single-contaminant regeneration recycling water systems, Chemical Engineering Science 62 (8) (2007) 2127-2138.

[16] N. Takama, T. Kuriyama, K. Shiroko, T. Umeda, Optimal water allocation in a petroleum refinery, Computers and Chemical Engineering 4 (4) (1980) $251-258$.

[17] M.M. El-Halwagi, A.A. Hamad, G.W. Garrison, Synthesis of waste interception and allocation networks, AIChE Journal 42 (11) (1996) 3087-3101.

[18] A. Alva-Argáez, A. Vallianatos, A. Kokossis, A multi-contaminant transshipment model for mass exchange network and wastewater minimization problems, Computers and Chemical Engineering 23 (10) (1999) 1439-1453.

[19] Z.A. Putra, K.A. Amminudin, Two-step optimization approach for design of a total water system, Industrial and Engineering Chemistry Research 47 (16) (2008) 6045-6057.

[20] C.H. Huang, C.T. Chang, H.C. Ling, C.C. Chang, A mathematical programming model for water usage and treatment network design, Industrial and Engineering Chemistry Research 38 (7) (1999) 2666-2679.

[21] R. Karuppiah, I.E. Grossmann, Global optimization for the synthesis of integrated water systems in chemical processes, Computers and Chemical Engineering 30 (4) (2006) 650-673.

[22] J.M. Ponce-Ortega, F. Nápoles-Rivera, M.M. El-Halwagi, A. Jiménez-Gutiérrez, An optimization approach for the synthesis of recycle and reuse water integration networks, Clean Technologies and Environmental Policy 14 (1) (2012) 133-151.

[23] C. Sotelo-Pichardo, J.M. Ponce-Ortega, M.M. El-Halwagi, S. Frausto-Hernandez, Optimal retrofit of water conservation networks, Journal of Cleaner Production 19 (14) (2011) 1560-1581.

[24] L.F. Lira-Barragán, J.M. Ponce-Ortega, M. Serna-González, M.M. El-Halwagi, Synthesis of water networks considering the sustainability of the surrounding watershed, Computers and Chemical Engineering 35 (12)(2011) 2837-2852.

[25] E. Rubio-Castro, J.M. Ponce-Ortega, M. Serna-González, A. Jiménez-Gutiérrez, M.M. El-Halwagi, A global optimal formulation for water integration in eco-industrial parks considering multiple pollutants, Computers and Chemical Engineering 35 (8) (2011) 1558-1574.

[26] E. Rubio-Castro, J.M. Ponce-Ortega, F. Nápoles-Rivera, M.M. El-Halwagi, M. Serna-González, A. Jiménez-Gutiérrez, Water integration of eco-industrial parks using a global optimization approach, Industrial and Engineering Chemistry Research 49 (20) (2010) 9945-9960.

[27] D.C.Y. Foo, Z.A. Manan, Y.L. Tan, Synthesis of maximum water recovery network for batch process systems, Journal of Cleaner Production 13 (15) (2005) 1381-1394.

[28] A. Rabie, M.M. El-Halwagi, Synthesis and scheduling of optimal batch water-recycle networks, Chinese Journal of Chemical Engineering 16 (3) (2008) 474-479.

[29] T. Majozi, Batch Chemical Process Integration: Analysis, Synthesis, and Optimization, Springer, Heidelberg, 2010.

[30] T. Majozi, An effective technique for wastewater minimization in batch processes, Journal of Cleaner Production 13 (15) (2005) 1374-1380.

[31] C.T. Chang, B.H. Li, Optimal design of wastewater equalization systems in batch processes, Computers and Chemical Engineering 30 (5) (2006) 797-806.

[32] K.F. Cheng, C.T. Chang, Integrated water network designs for batch processes, Industrial Engineering and Chemistry Research 46 (5) (2007) $1241-1253$.

[33] A.M. Shoaib, S.M. Aly, M.E. Awad, D.C.Y. Foo, M.M. El-Halwagi, A hierarchical approach for the synthesis of batch water network, Computers and Chemical Engineering $32(3)(2008) 530-539$

[34] C.L. Chen, J.Y. Lee, J.W. Tang, Y.J. Ciou, Synthesis of water-using network with central reusable storage in batch processes, Computers and Chemical Engineering 33 (1) (2009) 267-276.

[35] R.J. Zhou, L.J. Li, W. Xiao, H.G. Dong, Simultaneous optimization of batch process schedules and water-allocation network, Computers and Chemical Engineering 33 (6) (2009) 1153-1168.

[36] D.R. Monyane, T. Majozi, Long term scheduling techniques for wastewater minimization in multipurpose batch processes, Applied Mathematical Modelling 36 (5) (2012) 2142-2168.

[37] O. Adekola, T. Majozi, Wastewater minimization in multipurpose batch plants with a regeneration unit: multiple contaminants, Computers and Chemical Engineering $35(12)(2011) 2824-2836$.

[38] J.F. Gouws, T. Majozi, D.C.Y. Foo, C.L. Chen, J.Y. Lee, Water minimization technique for batch processes, Industrial and Engineering Chemistry Research 49 (19) (2010) 9165-9174

[39] T. Majozi, J.F. Gouws, A mathematical optimization approach for wastewater minimization in multipurpose batch plants: multiple contaminants, Computers and Chemical Engineering 33 (11) (2009) 1826-1840.

[40] J.F. Gouws, T. Majozi, Usage of inherent storage for minimization of wastewater in multipurpose batch plants, Chemical Engineering Science 64 (16) (2009) 3545-3554.

[41] J.F. Gouws, T. Majozi, M. Gadalla, Flexible mass transfer model for water minimization in batch plants, Chemical Engineering and Processing: Process Intensification 47 (12) (2008) 2323-2335.

[42] J.F. Gouws, T. Majozi, Impact of multiple storage in wastewater minimization for multicomponent batch plants: toward zero effluent, Industrial and Engineering Chemistry Research 47 (2) (2008) 369-379.

[43] T. Majozi, Storage design for maximum wastewater reuse in multipurpose batch plants, Industrial and Engineering Chemistry Research 45 (17) (2006) 5936-5943.

[44] T. Majozi, Wastewater minimization using central reusable water storage in batch plants, Computers and Chemical Engineering 29 (7) (2005) $1631-1646$.

[45] E. Kondilli, C.C. Pantellides, R.W.H. Sargent, A general algorithm for short-term schedulling of batch operations. I: MILP formulation, Computers and Chemical Engineering 17 (2) (1993) 211-227.

[46] C.T. Maravellias, I.E. Grossmann, New general continous-time state-task network formulation for short term scheduling of multipurpose batch plants, Industrial and Engineering Chemistry Research 42 (13) (2003) 3056-3074.

[47] H. Yeomans, I.E. Grossmann, A systematic modeling framework of superstructure optimization in process synthesis, Computers and Chemical Engineering 23 (6) (1999) 709-731.

[48] M.D. Shelley, M.M. El-Halwagi, Componentless design of recovery and allocation systems: a functionality-based clustering approach, Computers and Chemical Engineering 24 (9) (2000) 2081-2091.

[49] J.M. Ponce-Ortega, A.C. Hortua, M.M. El-Halwagi, A. Jiménez-Gutiérrez, A property-based optimization of direct recycle networks and wastewater treatment processes, AIChE Journal 55 (9) (2009) 2329-2344.

[50] J.M. Ponce-Ortega, M.M. El-Halwagi, A. Jimenez-Gutierrez, Global optimization for the synthesis of property-based recycle and reuse networks including environmental constraints, Computers and Chemical Engineering 34 (3) (2010) 318-330.

[51] F. Nápoles-Rivera, J.M. Ponce-Ortega, M.M. El-Halwagi, A. Jiménez-Gutiérrez, Global optimization of mass and property integration networks with in-plant property interceptors, Chemical Engineering Science 65 (15) (2010) 4363-4377. 
[52] J.M. Ponce-Ortega, F.W. Mosqueda-Jiménez, M. Serna-González, A. Jiménez-Gutiérrez, M.M. El-Halwagi, A property-based approach to the synthesis of material conservation networks with economic an environmental objectives, AIChE Journal 57 (9) (2011) 2369-2387.

[53] C. Deng, X. Feng, Targeting for conventional and property-based water network with multiple resources, Industrial and Engineering Chemistry Research 50 (7) (2011) 3722-3737.

[54] S.Y. Saw, L. Lee, M.H. Lim, D.C.Y. Foo, I.M.L. Chew, R.R. Tan, J.J. Klemes, An extended graphical targeting technique for direct reuse/recycle in concentration and propertybased resource conservation networks, Clean Technologies and Environmental Policy 13 (2)(2011) 347-357.

[55] H. Seingheng, R.R. Tan, J. Auresenia, T. Fuchino, D.C.Y. Foo, Synthesis of near-optimal topological constrained property-based water network using swarm intelligence, Clean Technologies and Environmental Policy 9 (1) (2007) 27-36.

[56] D.C.Y. Foo, V. Kazantzi, M.M. El-Halwagi, Z.A. Manan, Surplus diagram and cascade analysis technique for targeting property-based material reuse network, Chemical Engineering Science 61 (8) (2006) 2626-2642.

[57] D.C.Y. Foo, Z.A. Mananb, R.M. Yunus, R.A. Aziz, Synthesis of mass exchange network for batch processes. Part I: utility targeting, Chemical Engineering Science 59 (5) (2004) 1009-1026.

[58] D.K.S. Ng, D.C.Y. Foo, A. Rabie, M.M. El-Halwagi, Simultaneous synthesis of property-based water reuse/recycle and interception networks for batch processes, AIChE Journal $54(10)(2008) 2624-2632$.

[59] C.L. Chen, J.Y. Lee, D.K.S. Ng, D.C.Y. Foo, Synthesis of property-based resource conservation network in palm oil mills with time-varying process disturbance, Clean Technology Environmental Policy 13 (4) (2011) 625-632.

[60] A. Stankiewicz, J.A. Moulijn, Process intensification: transforming chemical engineering, Chemical Engineering Progress 96 (1) (2000) $22-34$.

[61] J.M. Ponce-Ortega, M.M. Al-Thubaiti, M.M. El-Halwagi, Process intensification: new understanding and systematic approach, Chemical Engineering and Processing: Process Intensification 53 (2012) 63-75.

[62] S. Mannan, Lees' Loss Prevention in the Process Industries, Fourth Edition: Hazard identification, Assessment and Control, Butterworth-Heinemann, Burlington, MA, USA, 2012.

[63] M. Gopalakrishnan, J.M. Ponce-Ortega, M.M. El-Halwagi, A systems approach for process simplification through process integration, Chemical Engineering and Technology 35 (7) (2012) 1262-1272.

[64] A. Brooke, D. Kendrick, A. Meeraus, GAMS User's Guide, The Scientific Press, USA, 2012

[65] L.A. Lopez-Maldonado, J.M. Ponce-Ortega, J.G. Segovia-Hernández, Multiobjective synthesis of heat exchanger networks minimizing the total annual cost and the environmental impact, Applied Thermal Engineering 31 (6-7) (2011) 1099-1113. 